\title{
Review of Schooling of Learners With Disabilities and the Manifestation of the Hidden Curriculum of Time
}

\author{
Theodoto Ressa, PhD \\ Wayne State University, Detroit, Michigan, United States \\ (iD) https://orcid.org/0000-0003-4599-921X
}

Contact: theodoto@hotmail.com

\section{Abstract}

Postsecondary outcomes remain difficult to attain despite their significance to learners with disabilities. This qualitative study investigated the impact of a hidden curriculum of time on the education of five undergraduate students with disabilities at a Carnegie Research One institution in the midwestern U.S. Participants in their quest for an education experienced a hidden curriculum of time in the form of physical impairments, educational costs of ill-health, and disability discrimination. The academic barriers participants encountered in reaching their educational goals suggest that addressing the hidden curriculum of time is essential for authentic inclusion and achievement of postsecondary education outcomes.

Keywords: disability; curriculum; school; transition; inclusion

Date Submitted: October 1, 2020 | Date Published: April 28, 2021

\section{Recommended Citation}

Ressa, T. (2021). Review of Schooling of Learners with Disabilities and the Manifestation of the Hidden Curriculum of Time. Journal of Educational Research and Practice, 11, 95-111. https://doi.org/10.5590/JERAP.2021.11.1.07

\section{Introduction}

Many learners with intellectual and developmental disabilities struggle to adapt to their new environment in life and therefore have a low quality of life. Upon high school completion, they experience challenges becoming employed, going to college, participating in leisure and recreation, living independently, and participating in community affairs; often, this is because the hidden curriculum of their education never prepared them for the realities of life. Some education plans set up students with disabilities for an unsuccessful adulthood, especially when educators and service providers responsible for the development and implementation of these plans have low expectations for the students and cherish the use of labels that invalidate these students in society (Berg et al., 2017; Schwarz, 2006). Accordingly, in the U.S., the highest rate of those with a low quality of life consists of members of the community of disabled people (U.S. Bureau of Labor Statistics, 2020; U.S. Senate 2014), mostly because of a lack of readiness skills and opportunities (McFarland et al., 2018).

Under current labor conditions, a college education is vital for individuals with disabilities, for it exposes them to experiences essential for getting and maintaining competitive employment. The employment rate of people 
with disabilities is higher among those who have a bachelor's degree (28.2\%) than those with less than a high school diploma (15.5\%) (U.S. Bureau of Labor Statistics, 2020). The employment rate of individuals with disabilities, regardless of education level, is still less than that of nondisabled individuals with a bachelor's degree or a high school diploma. The U.S. Bureau of Labor Statistics (2020) report revealed the employment rate of people with and without disabilities was $19.3 \%$ and $66.3 \%$, respectively, in 2019, and the unemployment rates for people with and without disabilities was $7.3 \%$ and $3.5 \%$, respectively. These disparities are exacerbated by the fact that a college education remains inaccessible to many children and youth with disabilities (hereby referred to as learners with disabilities unless differentiating groups) aspiring to pursue such (U.S. Bureau of Labor Statistics, 2020). Although successful postsecondary outcomes increase possibilities for quality of life, little is known about what constitutes successful education and transitions, prekindergarten through college $(\mathrm{P}-16)$, for learners with disabilities.

Many of the early interventions and accommodations in learning institutions focused on creating accessible physical settings (Barnard-Brak et al., 2010). Although there are studies on the varying needs of individuals who have visible disabilities, little of this research has focused on the climate and culture of institutions, and the education system remains unfavorable to individuals with disabilities. Unfortunately, few studies have attempted to comprehend the individual and institutional factors affecting schooling of students with disabilities (Ankeny \& Lehmann, 2011; Banks, 2014; Coduti et al., 2017; Connor, 2013; Hetherington et al., 2010; Knight et al., 2018). Consequently, little is known about the hidden curriculum of time and how it influences schooling and the transition to college of learners with disabilities. The main purposes of this paper are twofold: a) explore what a hidden curriculum in relation to learners with disabilities is, how it operates, how it constrains and hampers those students, and b) explicate the notion of time that pertains to this study. My aim is to identify any hidden curricula in order to identify educators' ways of addressing them, improve educational outcomes for learners with disabilities, and reduce the rate of those living on the margins of society and improve their quality of life. It was hypothesized that learners with disabilities have conspicuous conditions that make them vulnerable to institutional practices and schedules. My guiding question was: What kind of hidden curricula of time impact schooling of students with disabilities? This article provides some answers.

\section{Hidden Curriculum of Time}

Both time and curriculum have different meanings in different environments. Time is defined differently in different fields (e.g., philosophy, religion, science) and means different things in different locations (based on context, season, event, or activity) and to different groups (e.g., African, European, Chinese) (Carroll, 2010; Zeigler, 2008). Generally, time is theorized as an experience, an event, and a measuring instrument. See Exactly What is Time? (http://www.exactlywhatistime.com/). It is a qualitative and quantitative human experience (Ivey \& Hume, 1974; Le Poidevin, 2004) that can either be relative or relational (Núñez et al., 2012; St. Augustine, 2012). Time is also considered a mental arrangement that helps human beings experience their world (Bottini et al., 2015). In education, time is linked to rules and lessons and, therefore, it guides relations and interactions of teachers, staff, students, and their families (Elias, 1992; Luckham \& Schulte, 2011; Nordquist, 2020; Núñez et al., 2012; Piasecki, 2011; Russell, 1987). Different tools such as calendars and clocks are used to measure time, especially in a school environment (Bunnag, 2017; Kant, 2004).

On the other hand, a curriculum is what is taught, the implicit knowledge, skills, principles, and values embedded in multiple subjects that students learn in school (Levine, 1981). A "curriculum is a written document depicting the scope and arrangement of a projected educational program for a school (Beauchamp, 1981); or, curriculum is a plan for the education of learners" (Zais, 1976; cited in Nelms, 1991, p. 6). An official curriculum is tailored specifically to prepare students for the adult roles and responsibilities that are decided 
upon by experts as important for the survival of a community. It is an "explicit curricula that focus on substantive knowledge and skills" (McLean \& Dixit, 2018, p. 3). On the contrary, a hidden curriculum consists of values, norms, and practices that are conveyed without conscious intention during teaching and learning in school settings (Berg et al., 2017; McLean \& Dixit, 2018; Semper \& Blasco, 2018). Also, a hidden curriculum can refer to inexplicit expectations, outcomes, or messages resulting from the learning process. Oftentimes, the competencies of learners with disabilities (e.g., speaking, writing, or walking) are judged based on time. Those who move or write or think differently and quickly or slowly are speedily judged, labeled, segregated, and placed in special facilities (Danforth, 2014; Samuels, 2017). Then, a hidden curriculum of time is the period lost to learners with disabilities due to obstacles in their learning environment. Portelli (1993) outlines four main ways in which the term hidden curriculum is used:

a hidden curriculum as the unofficial expectations, or implicit but expected messages; a hidden curriculum as unintended learning outcomes or messages; a hidden curriculum as implicit messages arising from the structure of schooling; and a hidden curriculum as created by the students. (p. 345)

Berg et al.'s (2017) single bounded exploratory case study focused on the aspects of college life that are never explicitly taught but remain necessary to function in college settings. Their participants included students with intellectual and developmental disabilities and their guardians, instructors, administration, and transition specialist. Students were interviewed using Vineland Adaptive Behavior Scales-Second Edition (VINELAND-II), with self-reported answers in addition to surveys, document reviews, and classroom observations. Berg et al. (2017) concluded that the students were generally underprepared for postsecondary school and noted several gaps of importance regarding this lack of preparation that specifically related to the hidden curriculum of time. Informed by the findings, Berg et al. (2017) defined a hidden curriculum as "the often unspoken and unacknowledged content and skills that support academic and adult-level performance" (p. 2). Their use of hidden curriculum corresponds to Portelli's first definition, viewing the hidden curriculum as "unofficial expectations" (p. 345). Berg et al. (2017) view the concept of a hidden curriculum more positively, as something that could even be helpful. Those authors (2017) identify three main areas of hidden curriculum as: "adult-based system navigation, persisting challenges with adaptive behavior skills, and disability awareness and disclosure" (p. 4). An example of a hidden curriculum from the first area, adultbased system navigation, is students learning how to get around their school campuses. Also, students decreasing their dependency on school faculty is another form of hidden curriculum. The second area of a hidden curriculum consists of the persistent challenge to acquiring adaptive behavior skills, such as conceptual skills, social skills, and practical skills. All of these skills, or lack thereof, provided a challenge for students and faculty in the study. At the same time, technology was an example of a hidden curriculum that had a positive effect. Students with disabilities could use their "smart phones for mapping transportation routes and staying in contact with peers, advisers, instructors, and parents or guardians" (Berg et al., 2017, p. 5). An example of the disability awareness and disclosure area of a hidden curriculum was students not understanding how disabilities present challenges and that students should look to attain support to help overcome those challenges. Another example in this area was the negative stigma associated with disability and the self-depreciation that comes with it. Students often did not want to discuss their disability because they felt vulnerable. As one professor with a disability said, "[It] saddens me because society taught that... being disabled is bad" (Berg et al., 2017, p. 6). So, the hidden curriculum in this example is a good thing because it advocates for disability awareness. This can help destigmatize disability and help students learn within the prescribed time and least restrictive spaces.

McLean and Dixit (2018), who investigated the hidden curriculum implicit in informal adult education through self-help books, mention that hidden curricula "represent the diverse messages received and lessons learned through students' actual engagement with the processes of schooling" (p. 3), which corresponds to Portelli's third definition, as an "implicit message." McLean and Dixit (2018) mention that "what children and youth learn through their participation in educational institutions... that the experience of schooling lead 
children and youth to internalize certain norms and values not explicitly identified in formal curricula-norms and values such as deference to authority and conformity to peer expectations" (pp. 2-3). The non-intentional ideas that students learn by going to school may be good or bad. Some ideas that children encounter implicitly from hidden curricula can be "racist, classist, and sexist" (McLean \& Dixit, 2018, p. 4). In all age groups, from primary to postsecondary school students, an "educational" text exists that promotes sexist and racist social norms. Additionally, themes of a perfect society are promoted, where the goal is to fit in, and, if something goes wrong, one can only blame themselves. McLean and Dixit discuss this information when they state these texts include "beliefs that agencies of authority and hierarchical control are working in harmony with them, and that when problems arise, they have their own individual fortitude to rely on" $(2018$, p. 5). They also discuss the hidden curriculum from a diverse array of self-help books that various adults have read. This discussion has a more benevolent effect. Here, the hidden curriculum is to have a positive outlook on life. No matter the topic of the self-help book that was read, 6o percent of participants said they experienced "learning outcomes relating to positive thinking” (McLean \& Dixit, 2018, p. 8). Thus, hidden curricula may not always be a negative effect of education.

Hidden curriculum can lead to inclusion or exclusion of learners and determine their educational outcomes. When hidden curriculum becomes a tool of excluding learners with disabilities, the education system has become a means of punishing those that it considers unworthy. Education of children with disabilities was optional until 1975, when the 94th U.S. Congress enacted the Education for All Handicapped Children ActEAHCA (Danforth, 2014). Today, over seven million children with disabilities (14\% of the student population age 3-21) in the U.S. receive special education services (U.S. Department of Education, 2020). Whereas the purpose of EAHCA (currently the Individuals with Disabilities Education Improvement Act [IDEIA] of 2004) was to make public education accessible to learners with disabilities, in some situations, special education has evolved into a means of denying children with disabilities quality education. Ironically, Black children with disabilities are more likely to be punished than White children with disabilities (Baker, 2019) often because they do not fit into the education structure or meet the expectations and norms of educators, the majority of whom are Whites from middle-class households (Danforth, 2014). Learners are provided with education in order to give back to their community. Contemporary formal education involves school attendance and learning the official curriculum taught by trained and certified educators. An official curriculum has standardized learning activities (Knowles, 1980) that determine students' competency and progress from grade to grade to the time they exit school. Education that adopts community resources to nurture appropriate behaviors, whether formal or informal, is important for an individual and the community (Dewey, 1998). Appropriate education inculcates appropriate values that prepare learners for good citizenship. Whereas there has been a shift in education, moving from a teacher-centered approach, which views the instructor as a transmitter of information, to a student-centered approach, which recognizes the importance of what the student does (Michaels \& Ferrara, 2009; Semper \& Blasco, 2018), not much shift has occurred when it comes to the education of students with disabilities. And so, many still fail in school and life.

\section{Methods}

This qualitative study (Silverman, 2010) is a small case study drawn from a larger study that investigated students' P-16 education experiences (Ressa, 2016). Early accessibility initiatives focused on modifying institutional physical settings in order to accommodate students with physical disabilities such that their schooling, transitions, and integration were assumed to be easy. Since architectural changes in learning institutions have been ongoing, experiences of learners with disabilities can provide information about institutions' climate and culture and their preparedness to support the inclusion of learners with disabilities and train them to be productive adult citizens. Information about learners' conditions, identities, and wellbeing can provide insight into possible experiences in different school settings. 
To increase the credibility and validity of research findings, I triangulated educational experiences data by comparing the interviews, field notes of participants' observations, and reflections of information (e.g., records and forms) (Cohen et al., 2007). Maximizing participant anonymity and maintaining the integrity of data (e.g., in-depth interviews with students with disabilities) are important exercises in qualitative research (Saunders et al., 2015). Accordingly, I use pseudonyms throughout this paper to protect the identities of participants.

\section{Disability Studies}

Theoretically, my study was within the interpretive tradition. The basic tenet of interpretation requires descriptions of social spheres constructed through first-person accounts as told by social actors engaged in relevant activities and experiences, which are then curated or analyzed and interpreted by a researcher (Balsvik, 2017). I drew on the social/constructionist theory of disability in this research (Abberley, 1987). My theoretical framework adhered to two useful assumptions of traditional disability studies for understanding some relationships between transition support, services, and successes for learners with disabilities:

1. Disability and impairment are related constructs with distinct differences in meaning and lived experience. Impairment is considered a functional difference (e.g., sensory or mobility loss, traumatic brain injury, or cerebral palsy), and disability is considered the exclusion experienced by people with impairments that prevent them from full participation in society.

2. Structural barriers are a means of social exclusion of people with disabilities that prevent them from full inclusion in society (i.e., structures that contribute to segregated education, unemployment, or housing discrimination) (Abberley, 1987; Gabel \& Connor, 2014; Oliver, 1990).

This social model of disability puts forward the idea that disability is (largely) socially constructed (Abberley, 1987; Oliver, 1990). When approaching disability from the social model, the focus is on the ways that society both creates and perpetuates the disability (Gabel \& Connor, 2014). The social model of disability provides a way for me to both frame and define the academic factors that are described in this research. The history, politics, and meanings of disability and impairment are deeply entangled with the societal impulse for perfection (Osgood, 2008).

\section{Participants and Setting}

For this paper, I chose to present data from five undergraduate students (two females and three males) because their perspectives spoke directly about their academic challenges when navigating institutional structures. Participants' impairments preexisted high school graduation, they were all schooled in the U.S., all had access to the general education curriculum, and all were entitled to special education services during their $\mathrm{P}-12$ schooling period. Participants had an array of disabilities, many of which were conspicuous. At the time of this study, Ann, who had been diagnosed with cerebral palsy upon birth, was 21 years old. She was a second year majoring in biology and chemistry with the goal of joining a medical school. Ivy was diagnosed with Stickler syndrome before age five; she was 21 years old and majoring in psychology. Edd, who was diagnosed with spina bifida at birth, was 18 years old, in his first year of college majoring in linguistics, and interested in physics. Eli was legally blind and partially deaf in the left ear. He was 21 years old and in his third year pursuing a degree in computer and information science. Rob was a 19-year-old male who was diagnosed with Fragile X-associated tremor/ataxia syndrome (FXTAS), a neuro-muscular disease, and hydrotropic cardiomyopathy before age 10. He was in his second year pursuing a degree in management and industry exploration. 


\section{Data Collection and Analysis}

I used applied thematic analysis to identify, analyze, and interpret transcribed interview data to make meaning of participants' schooling experiences. I inputted data into NVivo software, version 11 (a qualitative data analysis computer software made by QSR International Pty Ltd., Victoria, Australia). During coding processes, I repeatedly read the transcripts (Ericsson \& Simon, 1993) and then tagged and labeled relationships and consequences to make meanings of participants' specific education and transition experiences (Gray, 2004). I used both inductive and deductive approaches to uncover elements I would categorize and delineate into themes (Guest et al., 2012). Guided by the disability studies framework, I interpreted data by contextually matching interviews with field notes from my reflective journal (Thomas, 1993). This allowed me to explain specific phenomena based on the language (i.e., words, phrases, or sentences) related to disability and education to rationalize the lived experiences of my participants. In the process, I was able to identify how participants positioned themselves in the learning environments and different aspects of the hidden curriculum of time that influenced understanding of their education and world (Stergiopoulos et al., 2018).

\section{Moments of Hidden Curricula of Time}

This study aimed to understand the factors that affect schooling of learners with disabilities. The themes that emerged from the data are physical impairments, educational costs of ill-health, and disability discrimination. I discuss each theme below.

\section{Physical Impairment}

Participants reported numerous physical and physiological difficulties. Impairments, fitful illnesses, distressing physical experiences, side effects of prescription drugs, frequent injuries, and hospitalizations led to erratic school attendance and missed classes and exams, which limited the participants' academic interactions. These contributed to low academic performance and stressful experiences. For example, Rob's condition, FXTAS syndrome and hypertrophic cardiomyopathy, manifested in elementary school. It affected his stamina, coordination, balance, and speech, which made it difficult for him to perform certain activities of daily living, such as bathing, toileting, laundry, or independently manipulating learning materials (e.g., gripping pens to write, holding tools, handling equipment like beakers and spatulas, and mixing chemicals). Rob reported that "bad eye-hand coordination [made it difficult to] pour things in science classes." Life was already hard because his muscle degeneration made him prone to fractures and fatigue and forced him to use a wheelchair. However, the wheelchair could only function in accessible settings, for example buildings with elevators or paved paths. These experiences limited his involvement in strenuous activities and transformed him from an autonomous individual to a dependent person. Rob also reported, "I needed... everyday help [starting in] sixth grade.”

While difficulties caused by physical impairments hindered participants' involvement in certain learning activities, physical barriers aggravated the situation. Ann and Edd, both wheelchair users because of cerebral palsy and spina bifida, respectively, experienced difficulties navigating inaccessible environments. High school settings with no ramps or with broken accessible door openers made schooling challenging. Both could use specific wheelchair-accessible routes outside and inside the school buildings. Broken accessible doorknobs or elevators at the end of the hallway and lack of accommodations, in general, increased the time of transitions from one class to another. It was not only time-consuming but also exhausting for Ann and Edd to maneuver through crowded bathrooms and hallways and to wait for the elevator operator. Edd reported being "late to class because hallways were crowded, or the elevator was busy, or I had to take some time for selfcare." Also, Ann's high school classrooms had a door at the back, and because it was difficult to pass in a wheelchair, she always sat at the back of the classroom, which again made learning challenging. Ann reported 
that although she could not "see the board, nobody in my class would even give me the notes from the board." Also, Ann said it was challenging doing biology and chemistry experiments on high laboratory tables while seated in the wheelchair.

Similarly, Ivy, who has Stickler syndrome and visual impairment, reported attending a high school where students switched seating positions every month. Every so often, she found herself seated at the back of the classroom, and without accommodations, she struggled to see the board. She also reported that she strained to read books and had to deal with stigma and teasing, which compromised her concentration and added to her educational problems. She said:

In elementary school, my eyes used to be worse than they are right now. Reading was difficult. And math [tests] are always timed. Though I understood it [the material], I couldn't finish it. In elementary school, we were reading books, and I literally held the book close to my face and kids would make fun of me.

The hidden curriculum of time was linked to settings and activities that do not consider participants' physical impairment. It takes a lot of effort for participants to invest in their education and transition to college. Unlike peers without disabilities who find the school infrastructure tailored to their needs, participants experienced functional challenges caused by the mismatch of personal health conditions and school structures. The challenges demanded much of their input in addressing this negative impact, more than what peers without disabilities would invest in their education.

\section{Educational Costs of Ill-health}

There are material and nonmaterial costs for schooling, including tuition, health insurance, fees for books, supplies, and facilities, such as laboratories and libraries. Students with disabilities also often incur other fees involving medication and assistive technologies and loss of resources, including loss of time. Both financial and nonfinancial costs of impairment, illnesses, and injuries can burden students and their families. Participants' early onset of ill-health caused loss of learning opportunities. Illnesses, injuries, and hospitalizations in many ways disrupt participants' schooling and learning; some are forced to drop class positions because of missed classes and tests. Meanwhile, this makes teachers and peers expect less from them. For instance, Ann reported missing "seven consecutive months of senior year, and teachers and parents were even not sure if [she] was going to graduate." To catch up academically, participants described working extra hard, which involves using free time and holidays to do schoolwork. This struggle to improve academic performance contributes to frustrations and fears, as Ann reflected:

coming out my sophomore year of high school, I was in a three-way tie for number one. It was frustrating to lose that one. I was almost number one. If I had not been sick at all, my performance was always way above par. So, for me, falling from one to twelfth was frustrating.

Participants reported that every academic plan they made was informed by the limitations imposed by the curriculum that did not match their impairments and the disabling impact of a lack of necessary accommodations. They described difficulties in making plans for education due to illness remissions and relapses for unpredictable periods; this roller coaster also made moving to postsecondary life costly, financially and timewise. Some participants were forced to forgo certain four-year universities or to postpone moving to college due to health complications. For example, Ann developed dystonia (i.e., involuntary contraction or movement of muscles) after exiting high school and had to postpone attending a 4-year college for 2 years. Then she was hospitalized for weeks after developing health complications during the first semester of college, and she was forced to drop a class. 
Similarly, the struggle to balance medical needs and academics cost Ivy many educational opportunities. Immediately after graduating high school, Ivy decided to address the stigmatizing medical issues that almost derailed her academic achievements and progress in high school. She reported: "[My] surgery was scheduled for the end of June, and then it was moved back like three weeks. [And] the timeline would not allow me to go [to a 4-year university] when I [was] discharged." As a result, she was afraid to move away from home. Instead, she attended a nearby community college "because that was the easy option ... [it was] ... 10 minutes away from my house; I just commuted." Like the rest of the participants, Ivy experienced the hidden curriculum of time associated with the educational costs of ill-health.

\section{Fear of Disability Discrimination}

Schools must be accessible structurally for learners with disabilities to belong to and learn; however, just as important are real and perceived disability prejudices that can hamper academic progress. In many cases, participants' learning was jeopardized more by inaccessible school and classroom environments than their impairments, but they often felt worried and guilty about their situation. Participants reported that inaccessible settings inculcated a fear of discrimination. Ann worried that peers and teachers might misinterpret her disabilities, emotions, and behaviors and limit her prospects for going to college and pursuing a career in medicine. She procrastinated in making decisions about her academic trajectory out of fear of disability biases. For instance, she deferred declaring her major after she got into college, and she feared her medical records could be used against her. She said:

There are some things in my medical records that could end up coming back to bite me. Like if they ask me about psychological records. I do have them because they are required by some of my doctors. But that doesn't mean that I have psychological issues. It bothers me as I prepare my application [to medical school]. Yes, like if you are disclosing your disability that you want to be assisted, then you must show your confidence to meet the gold standard on what is measured. So different med schools could ask me for different things with no standards on it.

Fear causes misunderstandings of students' impairments and erodes trust, particularly when students suspect that their disability is the basis of bias. It creates barriers that cost students' friendships and academic opportunities. Participants were stressed by knowing that their health conditions negatively affected their academic progress. For instance, Ann and Rob reported feeling stressed by the thought that their impairments might deteriorate and limit their academic opportunities and independent living if they did not go to college. They were concerned that their impairments might impede their college attendance and create academic and social gaps, and they worried that their nondisabled classmates would go on to college and leave them behind while they resolved their medical issues. Once in college, participants worried their ill-health conditions may be used to deny them opportunities to pursue their dreams in high-demanding professional fields such as medicine.

Impairments, hospitalizations, and disabilities hinder participants' continuous school attendance, mobility, and explorations of the world, which limit their academic interactions and development of social relations. The challenges of high school life elevated participants' insecurity and anxiety, which affected their attention and participation in learning activities and contributed to low academic performance. College life was much better than life at the $\mathrm{P}-12$ school level. However, participants still worried that their disability could derail their college education. In comparison to the era before disability laws (e.g., Section 504 of the Rehabilitation Act 1973, American with Disabilities Act [ADA] 1990, or IDEIA 2004), many learning institutions now have accessible infrastructures. Still, many others remain inaccessible to students due to structural and personal barriers. Thus, the hidden curriculum of time manifested itself in participants' fear of disability discrimination. 


\section{Reflecting on Hidden Curricula and Impact on Education of Learners with Disabilities}

Purposefully this paper explores what a hidden curriculum in relation to learners with disabilities is, how it operates, how it constrains and hampers them, and the notion of time that pertains to their schooling. Findings reveal that participants experienced academic barriers during their $\mathrm{P}-16$ schooling. Barriers are conditions that make it difficult for students to make progress toward or achieve their educational goals, while academic barriers are problems that make it difficult for students to participate in education. Academic barriers reveal the hidden curriculum of time that learners with disabilities face in their quest for postsecondary outcomes. The barriers faced and their endeavors to overcome them to achieve postsecondary outcomes shed light on several factors that affect successful educational experiences of learners with disabilities.

\section{Hidden Curriculum of Time Manifests in Physical Impairment}

Physical and psychological impairments negatively impact the education and transitions of learners with disabilities even in the face of self-determination (Ankeny \& Lehmann, 2011; Deci \& Ryan, 2008). Academic barriers are linked to problems because of participants' physical impairments, educational costs due to illnesses and injuries, and schooling under the shadow of fear of disability discrimination. Though externally induced, academic barriers manifest themselves in the form of learners' impairments. Physical impairments for students mean having reduced quality to participate in learning, which includes interactions and socialization that often enrich one's experiences necessary for (academic, personal, or social) problem-solving, inclusion, and belonging. A less-friendly environment aggravates physical impairments and makes it difficult for students to engage meaningfully in many academic activities. Illness also causes physical impairments. Besides, the educational costs of ill-health are rarely considered when it affects academic performance and successful transitioning $\mathrm{P}-16$.

Schooling is uniquely costly for learners with disabilities compared to students without disabilities. In addition to costs related to time, space, place, tuition, health insurance, fees for books, supplies, and facilities, learners with disabilities may incur other material and nonmaterial expenses (e.g., transportation costs and time spent in the doctors office), which may cause medical and academic imbalances and reduce the timeframe for many learning activities and events. The medical and academic imbalances delay students' learning, graduation, and transition to the next level. Educational costs may also lead to social costs in situations where learners with disabilities are denied inclusion in learning activities or fail to graduate on time and are left behind by their classmates due to illness or lost time.

Both physical impairments and the educational costs of ill-health predispose students to biases. Fear of disability discrimination can handicap learners with disabilities and lead to low academic performance and segregation. Real and perceived fear of disability discrimination jeopardizes schooling. When inaccessible environments rather than impairments hinder participants' learning, they live in fear of the outcome and so suffer discrimination in silence which again add to apprehensions that inhibit learning and networking. Fear on the part of learners with disabilities and the part of teachers erodes trust, interferes with teaching, increases the student's cognitive load, and is likely to harm the student's academic progress, which further creates hurdles for successful schooling and transitioning. Fear inadvertently adds to social and academic pressures that negatively consume students' time and lead to bad health. Ill-health also causes anxiety and fear of losing health care, especially in the U.S., where preexisting health conditions are increasingly and regularly debated in national politics. Awareness of the politics of health around preexisting conditions and fear of losing healthcare coverage can be a source of stress that again distracts learners with disabilities from their education. Thus, even as they pursue their education, impairment and disability can lurk in the minds of students causing unnecessary distraction and stress to the individual. 
Students with disabilities experience significantly lower postschool outcomes (Coduti et al., 2017; McFarland et al., 2018; U.S. Department of Labor, 2020) because some special education programs and transition plans are not designed to support their acquisition of essential knowledge and skills that influence a smooth transition from grade to grade to postsecondary life (Banks, 2014; Hetherington et al., 2010). Curricula and classroom norms can either be a source of encouragement that leads to inclusion or punishment that leads to exclusion (Baker, 2019). Often, many learners with disabilities, especially learners of color, are punished at a disproportionate rate compared to students without disabilities for issues that educators can simply reteach or ignore, thus causing them to fail in achieving academic outcomes (Mendoza et al., 2019). The hidden curriculum of time also includes intentional or unintentional biases that learners with disabilities experience at the hands of educators (Blanchett, 2016), for they affect them educationally when they determine their inclusion or exclusion from class activities. Punishment happens when teachers' everyday behaviors act as an underlying message to their students that they do not specifically present but rather intimate. For instance, when a student in a wheelchair is made to sit at the back of the classroom (e.g., as in the case of my participant, Ann) where they are less accessible to teachers stationed at the front, they may be driven to adopt unconventional means of getting teacher's attention. It may be inappropriate when a student with limited hand functions shouts out their answer to get the teacher's attention in a class where students without disabilities raise their hands. It may be even more challenging for students with functional limitations who may rely on use of technology (e.g., a switch and blinker) to get the teacher's attention. Even though a student may have limited hand functions and an inability to raise their hand or sit at a position where they are accessible to the teacher and peers, the teacher may consider their lack of participation as a failure to adhere to classroom norms and punish them with a low participation grade. These discrete acts of the same behavior may be perceived as conflicting instructions to a student with disabilities, especially if they are expected to learn and generalize the behavior (i.e., apply it to all of this teacher's and other teachers' classes).

\section{Hidden Curriculum of Time Manifests in Educational Costs of Ill-Health}

Over 20\% of children and adolescents live with ill-health (Yazdani \& Zeltzer, 2013) that affects their education (Oppenheimer, 2018). Unfortunately, learners with disabilities often are treated as patients by educators and peers just because of their ailments, and their impairments are seen as costly to their education, and, therefore, they are regarded as incapable of succeeding in school. As a result, they are denied educational opportunities needed for achieving postsecondary outcomes. Oftentimes, learners with disabilities do not learn their $\mathrm{P}-12$ system of education in a manner that allows them to generalize their experiences in postsecondary life because they are shielded from realities and underprepared for challenges: the $\mathrm{P}-12$ system tells them exactly what to do; the educational experience is basically handed to them (Berg et al., 2017). In turn, this may affect their postsecondary outcomes (e.g., in college) because students are expected to be able to navigate an entirely new world with unique social norms, values, and expectations. Berg et al. (2017) found that students with intellectual and developmental disabilities struggled with "adult-based system navigation" (2017, p. 4) because, in moving from a public school system to a postsecondary education (PSE) institution, they had little to no understanding of the bureaucracy of postsecondary academic settings. They were unconfident, insecure, and unsure who to ask when they needed help and were unaccustomed to the independence that was expected of them in terms of meeting their basic needs. There were also "persisting challenges with adaptive behavior skills" (Berg et al., 2017, p. 5). Coming from special education classes, many students had not developed the conceptual, practical, and social skills necessary to succeed in a postsecondary educational system. They lacked experience with being challenged academically, taking care of themselves in areas such as transportation, hygiene, and money management, and had trouble navigating unfamiliar social scenarios. Finally, there was also the issue of "disability awareness and disclosure" (Berg et al., 2017, p. 6). Because they had not been involved in their own educational trajectory, many students had little awareness of their own disabilities and were unsure of their strengths and areas of need. Other students, aware of the stigma surrounding disability, struggled with disclosure. These three broad areas all relate to the "unofficial expectations" (Portelli, 1993, p. 345) of the hidden curriculum that posed particular issues for students with 
intellectual and developmental disabilities. Berg et al. (2017) conclude: "A combination of low performance expectations, overreliance on adult support... and limited variety in classroom student population have fostered dependency that persisted into PSE" (Berg et al., 2017, p. 6-7). An environment of low expectations and dependency (as is often found in segregated special education classrooms) seems to have affected students in PSE by depriving them of the tools to navigate the hidden curriculum.

Students with disabilities transitioning to postsecondary life need to have developed a range of repertoires for independent living and decision making. However, many grow up either neglected or sheltered and dependent on their families, educators, and professionals before leaving high school, making it difficult to acquire the necessary repertoires for independent life in postsecondary life (Berg et al., 2017). As McClean and Dixit (2018) found, the use of self-help books can create positive thinking and feelings for students. "Learning from this hidden curriculum may enable some readers to adjust themselves more happily to their circumstances, but it does not encourage them to find collective or structural ways to change those circumstances" (McLean \& Dixit, 2018, p. 13). Unfortunately, learners with disabilities are seldom given choices or options to foster their thinking. This form of a hidden curriculum boxes them in and, finally, caps their abilities and experiences. Children and youth with disabilities can realize post-school outcomes when provided an education that nurtures experiences needed for adult life (Dewey, 1998; McLean \& Dixit, 2018). These experiences can be realized when educators adopt pedagogical practices that go beyond teaching information that students need to memorize to pass a test (Biesta, 2013) and allow students to learn by doing in order to enrich their experiences to the extent that they can practice learned information independently (Dewey, 1998). Dewey believed that human beings learn through a "hands-on" approach (Dewey, 1998), and this notion is relevant today, particularly when it comes to the education of learners with disabilities.

\section{Hidden Curriculum of Time Manifests in Fear of Disability Discrimination}

In contrast to most teachers' behavior, participants in my study consider the inaccessible environment and not their impairments the problem that hinders their learning and think that with proper accommodations, they can remain engaged. This teacher-student contradictory belief is the foundation of an argument made by disability studies scholars (e.g., Danforth, 2014; Gabel \& Connor, 2014) that what learners with disabilities need most to succeed in life is inclusion and belonging. Unlike many segregated learners with disabilities, participants in my study are schooled in inclusive learning environments, and this can be deduced to have contributed to their successes. The principle of the least restrictive environment (LRE; IDEIA 2004) requires teaching students in the settings that maximize their potential, but it is a widely contentious and abused principle. Even though IDEIA embraces disability as a natural human phenomenon, some educators often exclude learners with disabilities out of inexperience, fear, apparent lack of resources and services, or bias (Agran et al., 2020; Danforth, 2014).

Exclusion of learners with disabilities from schooling processes because of inaccessible settings should not happen. Still, biased cultural practices and structural, social, and physical barriers negatively control the participation of learners with disabilities in education (Danforth, 2014; Gabel \& Connor, 2014). A Disability Studies framework would refer to such academic barriers as disabling (Baglieri et al., 2011; Oliver, 1990). Academic barriers point to systemic ableism in which some professionals are agents (Abberley, 1987; Agran et al., 2020). Biased cultural practices are socially constructed to create binaries of normal/abnormal, able/disable, and valid/invalid, and to attach value on bodies so that those who do not fit the prime human characteristics of "perfection" are labeled deviant and marked for dehumanization (Davis, 1995).

Inclusion is a commitment to educating all children in the general classrooms and holding them to high expectations (Agran et al., 2020). Inclusive education involves bringing services and support to learners with disabilities instead of having them segregated or pulled out from learning opportunities with their peers without disabilities (Baglieri et al., 2011; Danforth, 2014; Gabel \& Connor, 2014). Disability studies supports educating labeled students in non-segregated settings from a civil rights stance (Danforth, 2014). This is 
because inclusion empowers learners with disabilities. Nurturing inclusion is both a conviction that disability is a natural phenomenon and that a commitment to disability culture is needed to change biased practices against learners with disabilities (Agran et al., 2020; Davis, 1995; McDermott \& Varenne, 1995). Successful inclusion of learners with disabilities depends on the principles that guide inclusive education, which is that all children belong, all children learn in different ways, and it is every child's right to be included (Danforth, 2014). It also depends on a positive climate and culture, availability and efficient use of resources, open communication between stakeholders in education, school-home partnerships, collaboration of teachers and families, and humane treatment of all students (Michaels \& Ferrara, 2009; Wagner et al., 2012). Additionally, the success of inclusive education depends on the belief that every child is unique, that teaching and learning should be flexible to address students' needs, and that the one-fits-all curriculum fails to consider individual differences. Whereas deficit culture causes discrimination (McDermott \& Varenne, 1995) and failure of learners with disabilities, inclusion contributes to academic enablers (e.g., positive personal qualities-selfdetermination; Ankeny \& Lehmann, 2011; Deci \& Ryan, 2008).

Academic barriers in the era of disability laws are a mockery to learners with disabilities. Thus, teachers should adopt the strategy of nurturing reciprocal relationships with students in order to allow the development of respectful interactions that enable the sharing of experiences (Dewey, 1998; Semper \& Blasco, 2018). In this way, educators become the coaches, mentors, and facilitators of learning that support students through real-life experiences (Dewey, 1998). Often, learners with disabilities experience learning issues when real learning fails to happen because they do not trust their teachers due to low expectations and outright prejudice (Berg et al., 2017; Danforth, 2014; Gabel \& Connor, 2014). Children with disabilities come to school with rich experiences that when tapped benefit the whole class, including educators (Moll et al., 1992). Unfortunately, oftentimes the culture of deficit hinders student and teachers' positive relationships (Berg et al., 2017; Danforth, 2014; Gabel \& Connor, 2014; McDermott \& Varenne, 1995). Teachers will always be learning from their learners with disabilities and therefore growing professionally; therefore, it is important that they should also explicitly communicate implicit time-related information to their students in order to help them understand life (Berg et al., 2017; Semper \& Blasco, 2018).

\section{Conclusion}

A curriculum consists of all the decided-upon content taught throughout the school year that was intended to be taught, while a hidden curriculum is unintentional information imparted in the process of teaching and learning. A hidden curriculum is harmful to learners with disabilities and educators when the content is left to happen without being questioned. Participants in this study were clear that their disabilities impact every educational decision they make about their postsecondary goals. They recount pleasure accompanied by suffering during schooling and transitions that evoke memories of biases and learning time lost due to medical interventions or illness. Alternatively, results show that these individuals use significant inner strength to counteract the barriers they face. Then, whenever possible, the hidden curriculum should be taken out of the learning process because teachers subliminally share their own personal agenda and opinions with their students, while the school system is unaware of this. Still, it may not be possible to completely get rid of all the unintended lessons that students learn because of the simple fact that people often perceive what they want to see, hear, smell, taste, or feel, and, even if one does not intend for someone to take what they say the wrong way, they may do so. Therefore, teaching learners with disabilities to critically consume information can help reduce the negative impacts caused by hidden curricula of time, such as low academic performance and high school dropout or indiscipline issues.

The findings of the study have some implications for the educational processes of students with a physical disability moving to postsecondary life and outline many barriers to education and the transition despite IDEIA 2004 and ADA 1990 legislations that forbade discrimination toward people with disabilities in learning 
institutions. Participants in my study managed to transition to college in the face of barriers and remained steadfast in their quest for education and a better adult life through self-determination. However, there remains a need to focus on institutional barriers in terms of cultural orientations embedded in the curriculum of time that prevent administrators and educators from creating enabling environments for students with disabilities.

This study is limited in that it was informed by the experiences of five undergraduate learners with disabilities. Therefore, these findings may not be reflective of the body of students with disabilities locally and globally. Thus, more research is needed with a more diverse and larger population. Also, I focused on the interaction of disability and the academic domain, although a variety of micro- and macro-factors (e.g., pandemics, disasters, economic recession and booms and therefore school funding) are at play as learners with disabilities pursue education. In this light, there is a need for other research to focus on the interplay of these factors and how they impact learners with disabilities' educational achievements. 


\section{References}

Agran, M., Jackson, L., Kurth, J. A., Ryndak, D., Burnette, K., Jameson, M., Zagona, A., Fitzpatrick, H., \& Wehmeyer, M. (2020). Why aren't students with severe disabilities being placed in general education classrooms: Examining the relations among classroom placement, learner outcomes, and other factors. Research \& Practice for Persons with Severe Disabilities, 45(1), 4-13. https://doi.org/10.1177/1540796919878134

Ankeny, E. M., \& Lehmann, J. P. (2011). Journey toward self-determination: Voices of students with disabilities who participated in a secondary transition program on a community college campus. Remedial and Special Education, 32(4), 279-289. https://doi.org/10.1177/0741932510362215

Abberley, P. (1987). The concept of oppression and the development of a social theory of disability. Disability, Handicap, \& Society, 2(1), 5-19. https://doi.org/10.1080/02674648766780021

Baker, T. L. (2019). Reframing the connections between deficit thinking, microaggressions, and teacher perceptions of defiance. The Journal of Negro Education, 88(2), 103-113. https://doi.org/10.7709/jnegroeducation.88.2.0103

Balsvik, E. (2017). Interpretivism, first-person authority, and confabulation. Philosophy of the Social Sciences, 47(4-5), 311-329. https://doi.org/10.1177/0048393117705297

Baglieri, S., Bejoian, L. M., Broderick, A. A., Connor, D. J., \& Valle, J. (2011). [Re]claiming "Inclusive Education" toward cohesion in educational reform: Disability studies unravels the myth of the normal child. Teachers College Record, 113(10), 2122-2154. https://www.tcrecord.org/Content.asp?ContentId=16428

Banks, J. (2014). Barriers and supports to postsecondary transition: Case studies of African American students with disabilities. Remedial and Special Education, 35(1), 28-39. https://doi.org/10.1177/0741932513512209

Barnard-Brak, L., Lechtenberger, D. A., \& Lan, W. Y. (2010). Accommodation strategies of college students with disabilities. Qualitative Report, 15(2), 411-429. https://files.eric.ed.gov/fulltext/EJ875262.pdf

Berg, L. A., Jirikowic, T., Haerling, K., \& MacDonald, G. (2017). Navigating the hidden curriculum of higher education for postsecondary students with intellectual disabilities. The American Journal of Occupational Therapy, 71(3), 1-9. https://doi.org/10.5014/ajot.2017.024703.

Biesta, G. (2013). Receiving the gift of teaching: From "learning from" to "being taught by." Studies in Philosophy and Education, 32(5), 449-461. https://doi.org/10.1007/s11217-012-9312-9

Blanchett, W. J. (2016) Disproportionate representation of African American students in special education: Acknowledging the role of white privilege and racism. Educational Researcher, 35(6), 24-28. https://doi.org/10.3102/0013189x035006024

Bottini, R., Crepaldi, D., Casasanto, D., Crollen, V., \& Collignon, O. (2015). Space and time in the sighted and blind. Cognition, 141, 67-72. https://doi.org/10.1016/j.cognition.2015.04.004

Bunnag, A. (2017). The concept of time in philosophy: A comparative study between Theravada Buddhist and Henri Bergson's concept of time from Thai philosophers' perspectives. Kasetsart Journal of Social Sciences, 4O(1), 1-7. https://doi.org/10.1016/j.kjss.2017.07.007

Carroll, S. M. (2010). From eternity to here: The quest for the ultimate theory of time (pp. 54-55). Dutton.

Coduti, W. A., Herbert, J. T., Chiu, H., \& Döke, D. A. (2017). College preparation program for high school youth who are blind: The summer academy. Journal of Postsecondary Education and Disability, 3O(3), 269-282. https://files.eric.ed.gov/fulltext/EJ1163961.pdf

Cohen, L., Manion, L., \& Morrison, K. (2007). Research methods in education. Routledge Falmer. 
Connor, D. J. (2013). Sink or swim: Managing the academic transition to college for students with learning disabilities. Journal of College Student Retention: Research, Theory and Practice, 15(2), 269-292. https://doi.org/10.2190/CS.15.2.g

Danforth, S. (2014). Becoming a great inclusive educator. Peter Lang.

Davis, L. (1995). Enforcing normalcy: Disability, deafness, and the body. Verso.

Deci, E. L., \& Ryan, R. M. (2008). Self-determination theory: A macrotheory of human motivation, development, and health. Canadian Psychology, 49(3), 182-185. https://doi.org/10.1037/ao012801

Dewey, J. (1998). Experience and education. MacMillan

Elias, N. (1992). Time: An essay. Blackwell Publishers.

Ericsson, K. A., \& Simon, H. A. (1993). Protocol analysis: Verbal reports as data. MIT Press.

Gabel, S., \& Connor, D. J. (2014). Disability and teaching. Routledge.

Gray, D. E. (2004). Doing research in the real world. Sage Publications.

Guest, G., MacQueen, K. M., \& Namey, E. E. (2012). Applied thematic analysis. Sage Publications.

Hetherington, S., Durant-Jones, L., Johnson, K., Nolan, K., Smith, E., Taylor-Brown, S., \& Tuttle, J. (2010). The lived experiences of adolescents with disabilities and their parents in transition planning. Focus on Autism and Other Developmental Disabilities, 25(3), 163-172. https://doi.org/10.1177/1088357610373760

Ivey, D. G., \& Hume, J. N. P. (1974). Physics. Ronald Press.

Kant, I. (2004). The Critique of Pure Reason (2nd ed.). (J. M. D. Meiklejohn, Trans.). eBooks@Adelaide. (Original work published 1787).

Knight, W., Wessel, R. D., \& Markle, L. (2018). Persistence to graduation for students with disabilities: Implications for performance-based outcomes. Journal of College Student Retention: Research, Theory and Practice, 19(4), 362-380. https://doi.org/10.1177/1521025116632534

Knowles, M. (1980). From andragogy to pedagogy. Association Press.

Le Poidevin, R. (2004). The experience and perception of time. In E. N. Zalta (Ed.), The Stanford encyclopedia of philosophy. https://plato.stanford.edu/archives/sum2019/entries/time-experience/

Levine, A. (1981). Handbook on undergraduate curriculum. Jossey-Bass.

Luckham, D., \& Schulte, R. (Eds.). (2011). Event processing glossary-Version 2.o. Real time intelligence \& complex event processing. http://www.complexevents.com/2011/08/23/event-processing-glossaryversion-2/

McFarland, J., Cui, J., \& Stark, P. (2018). Trends in high school dropout and completion rates in the United States: 2014 (NCES 2018-117). U.S. Department of Education. National Center for Education Statistics. https://nces.ed.gov/pubs2019/2019117.pdf

McDermott, R., \& Varenne, H. (1995). Culture as disability. Anthropology \& Education Quarterly, 26(3), 324-348. https://doi.org/10.1525/aeq.1995.26.3.05x0936z

McLean, S., \& Dixit, J. (2018). The power of positive thinking: A hidden curriculum for precarious times. Adult Education Quarterly, 68(4), 280-296. https://doi.org/10.1177/0741713618777817

Mendoza, M., Blake, J. J., Marchbanks, M. P., \& Ragan, K. (2019). Race, gender, and disability and the risk for juvenile justice contact. The Journal of Special Education, 53(4), 226-235. https://doi.org/10.1177/0022466919845113 
Michaels, C. A., \& Ferrara, D. L. (2009). Promoting post-school success for all: The role of collaboration in person-centered transition planning. Journal of Educational and Psychological Consultation, 16(4), 287-313. https://doi.org/10.1207/s1532768Xjepc1604_4

Moll, L. C., Amanti, C., Neff, D., \& Gonzalez, N. (1992). Funds of knowledge for teaching: Using a qualitative approach to connect homes and classrooms. Theory into Practice, 31(2), 132-141. https://doi.org/10.1080/00405849209543534

Morningstar, M. E., Kurth, J. A., \& Johnson, P. J. (2017). Examining national trends in educational placements for students with significant disabilities. Remedial and Special Education, 38(1), 3-12. https://doi.org/10.1177/0741932516678327

Nelms, T. P. (1991). Has the curriculum revolution revolutionized the definition of curriculum? Journal of Nursing Education, 3o(1), 5-8. https://doi.org/10.3928/0148-4834-19910101-04

Nordquist, R. (2020). Definition and examples of narratives in writing. ThoughtCo. https://www.thoughtco.com/narrative-composition-term-1691417

Núñez, R., Cooperrider, K., Doan, D. \& Wassmann, J. (July 1, 2012). Contours of time: topographic construals of past, present, and future in the Yupno Valley of Papua New Guinea. Cognition, 124(1), 25-35. https://doi.org/10.1016/i.cognition.2012.03.007

Oliver, M. (1990). The politics of disablement: A sociological approach. St. Martin's Press.

Oppenheimer, S., Krispin, O., Levy, S., Ozeri, M., \& Apter, A. (2018). The impact of coping patterns and chronic health conditions on health-related quality of life among children and adolescents. European Journal of Pediatrics, 177(6), 935-943. https://doi.org/10.1007/s00431-018-3146-6

Osgood, R. L. (2008). The history of special education: A struggle for equality in American public schools. Praeger Publishers.

Piasecki, D. J. (2011). Saving warehouse space. Ops Publishing.

Portelli, J. P. (1993). Exposing the hidden curriculum. Journal of Curriculum Studies, 25(4), 343-358. https://doi.org/10.1080/0022027930250404

Ressa, T. W. (2016). The path to college: Transition experiences of students with disabilities. [Unpublished doctoral thesis] The Ohio State University Columbus. http://rave.ohiolink.edu/etdc/view?acc num $=0$ su1462887244

Russell, D. W., Altmaier, E., \& Van Velzen, D. (1987). Job-related stress, social support, and burnout among classroom teachers. Journal of Applied Psychology, 72(2), 269-274. https://doi.org/10.1037/00219010.72.2.269

Samuels, E. (2017). Six ways of looking at crip time. Disability Studies Quarterly, 17(3). https://doi.org/10.18061/dsq.v37i3.5824

Saunders, B., Kitzinger, J., \& Kitzinger, C. (2015). Anonymising interview data: Challenges and compromise in practice. Qualitative Research, 15(5), 616-632. https://doi.org/10.1177/1468794114550439

Schwarz, P. (2006). From disability to possibility: The power of inclusive classrooms. Heinemann.

Semper, J. V. O., \& Blasco, M. (2018, September 1). Revealing the hidden curriculum in higher education. Studies in Philosophy \& Education, 37(1), 481-496. https://doi.org/10.1007/s11217-0189608-5

Silverman, D. (2010). Doing qualitative research: A practical handbook. SAGE. 
Stergiopoulos, E., Fernando, O., \& Martimianakis, M. A. (2018). "Being on both sides": Canadian medical students' experiences with disability, the hidden curriculum, and professional identity construction. Academic Medicine, 93(10), 1550-1559. https://doi.org/10.1097/acm.0000000000002300

St. Augustine. (2012). The confessions of Saint Augustine. (E. B. Pusey, Trans.). Simon \& Brown.

Thomas, J. (1993). Doing critical ethnography. Sage Publications.

U.S. Department of Education. (n.d.). Special education-technical assistance on state data collection. https://www2.ed.gov/programs/osepidea/legislation.html

U.S. Bureau of Labor Statistics. (2020). Persons with a disability: Labor force characteristics-2019. https://www.bls.gov/news.release/archives/disabl_02262020.pdf

U. S. Senate. (2014). Fulfilling the promise: Overcoming persistent barriers to economic self-sufficiency for people with disabilities. Majority Committee Staff Report. Committee on Health, Education, Labor \& Pensions (Tom Harkin, Chairman). https://www.help.senate.gov/imo/media/doc/HELP\%20Committee\%20Disability\%20and\%20Pover ty\%20Report.pdf

Wagner, M., Newman, L., Cameto, R. (2012). A national picture of parent and youth participation in PE and transition meetings. Journal of Disability Policy Studies, 23(3), 140-155. https://doi.org/10.1177/1044207311425384

Yazdani, S., \& Zeltzer, L. (2013). Treatment of chronic pain in children and adolescents. Pain Management, 3(4), 303-314. https://doi.org/10.2217/pmt.13.25

Zeigler, K. (2008). Getting organized at work: 24 lessons for setting goals, establishing priorities, and managing your time (mighty manager). McGraw-Hill Education.

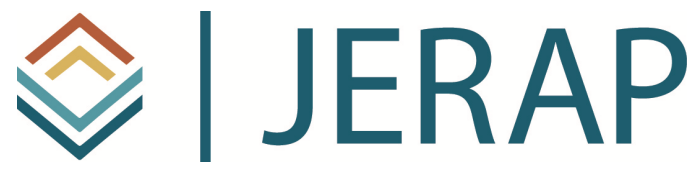

The Journal of Educational Research and Practice is a peerreviewed journal that provides a forum for studies and dialogue about developments and change in the field of education and learning. The journal includes research and related content that examine current relevant educational issues and processes. The aim is to provide readers with knowledge and with strategies to use that knowledge in educational or learning environments. JERAP focuses on education at all levels and in any setting, and includes peer-reviewed research reports, commentaries, book reviews, interviews of prominent individuals, and reports about educational practice. The journal is sponsored by The Richard W. Riley College of Education and Leadership at Walden University, and publication in JERAP is always free to authors and readers. 